\title{
A DESTRUIÇÃO DO SÍTIO ARQUEOLÓGICO "NOVA CIDADE" POR OBRA DO PODER PÚBLICO NA CIDADE DE MANAUS
}

\author{
ADRIANA OLIVEIRA DE AZEVEDO \\ MARCELA MATOS FERNANDES DE OLIVEIRA \\ MÁRCIO AUGUSTO FERREIRA MONTEIRO
}




\title{
A DESTRUIÇÃO DO SÍTIO ARQUEOLÓGICO "NOVA CIDADE" POR OBRA DO PODER PÚBLICO NA CIDADE DE MANAUS
}

\author{
Adriana Oliveira de Azevedo ${ }^{1}$ \\ Marcela Matos Fernandes de Oliveira ${ }^{2}$ \\ Márcio Augusto Ferreira Monteiro ${ }^{3}$
}

\section{RESUMO}

O presente artigo objetiva o exame das repercussões ambientais decorrentes da construção do Projeto Habitacional "Nova Cidade", em Manaus, Amazonas, erguido sobre um dos maiores sítios arqueológicos da América Latina. Tal circunstância, que tem o condão de conferirlhe a justa expectativa de ser um cenário capaz de revelar um pouco mais acerca da pré-história do Amazonas, mormente sobre os seus primeiros habitantes, foi ignorada ante a ausência do Estudo Prévio de Impacto Ambiental, bem como das autorizações e licenças pertinentes à obra, o que resultou na determinação de medidas reparadoras e mitigadoras dos danos ambientais causados.

Palavras-Chave: Sítio Arqueológico Nova Cidade. Patrimônio Cultural. Estudo Prévio de Impacto Ambiental.

1 Coordenadora da Assessoria Técnico-Jurídica da Casa Civil, da Prefeitura de Manaus. Advogada. Professora Universitária da Escola Superior Batista do Amazonas. Especialista em Auditoria e Controle Interno pela Universidade do Estado do Amazonas e em Direito Processual Civil pela Universidade Federal do Amazonas. Mestranda em Direito Ambiental pela Universidade do Estado do Amazonas. Membro do Centro de Estudos em Direito Ambiental da Universidade do Estado do Amazonas. E-mail: acajdrika@hotmail.com.

2 Procuradora-Geral Adjunta da Câmara Municipal de Manaus. Advogada. Especialista em Direito e Processo Penal pela Universidade Federal do Amazonas. Mestranda em Direito Ambiental pela Universidade do Estado do Amazonas. Membro do Centro de Estudos em Direito Ambiental da Universidade do Estado do Amazonas. E-mail: mmfo.am@hotmail.com.

3 Analista Judiciário do Tribunal de Justiça do Amazonas. Especialista em Direito Processual Civil pela Universidade Federal do Amazonas. Mestrando em Direito Ambiental pela Universidade do Estado do Amazonas. Membro do Centro de Estudos em Direito Ambiental da Amazônia. E-mail: marcio.monteiro@tjam.jus.com.br. 


\begin{abstract}
This article aims at examining the environmental impacts resulting from the construction of the Housing Project "New Town" in Manaus, Amazonas, built on one of the largest archaeological sites in Latin America. This circumstance, which has the power to give it a fair expectation of being able to reveal a scenario about the prehistory of the Amazon, especially about their earliest inhabitants, was ignored due to the absence of the Preliminary Environmental Impact Study as well as the relevant authorizations and licenses to the work, which resulted in the determination of remedial and mitigation measures of environmental damage.
\end{abstract}

Keywords: New Archaeological City. Cultural Heritage. Preliminary Environmental Impact Study.

\title{
1 INTRODUÇÃO
}

Reconhecido como direito fundamental pela Constituição de 1988, o meio ambiente ecologicamente equilibrado é também um dever atribuído à coletividade e ao Poder Público. Nesse sentido, o comportamento social e as políticas de Estado devem guardar sintonia com o mandamento constitucional, de modo a buscar a adoção de medidas que evitem a ocorrência de quaisquer desvios capazes de comprometer esse desiderato.

Para Silva (1994), o legislador constituinte, ao instituir normas dotadas de marcante conteúdo axiológico e inquestionável viés inspirador para o ordenamento jurídico, em atenção aos anseios sociais, buscou garantir um piso mínimo de direitos considerados indispensáveis para a qualidade de vida, dentre os quais figuram o direito à moradia e o meio ambiente 
sadio.

Notadamente, em nosso cotidiano, não são raras as vezes em que nos deparamos com situações de aparente conflito entre direitos fundamentais; e, nessas circunstâncias, sempre pairam dúvidas sobre qual deles deve prevalecer.

Campos (2004) relata que, apesar de constituírem o consagrado alicerce jurídico-normativo de nosso país, os direitos fundamentais não são ilimitados ou absolutos, o que faz com que esse caráter de relatividade deva ser aferido minuciosamente, de acordo com o caso concreto, mediante um juízo de ponderação.

Todavia, mesmo a técnica da ponderação encontra limites de observância obrigatória, para que não resulte em equívocos capazes de macular o núcleo essencial de cada direito, o que inevitavelmente implicaria ofensa à própria Constituição.

Essa questão serviu para dirimir conflito entre o direito fundamental à moradia (art. $6^{\circ}$ da CRFB, de 1988) e a proteção ao patrimônio cultural (art.216, V, da CRFB, de 1988).

Visando à construção de casas populares para aumentar a oferta de moradia ordenada e dotada de infraestrutura (redes de água, luz, telefonia, esgoto, ruas, calçadas, meio fio), o Governo do Estado do Amazonas, por meio da Superintendência de Habitação e Assuntos Fundiários (SUHAB), deu início ao processo licitatório para a execução da obra denominada "Projeto Habitacional Nova Cidade".

Ocorre que a construção do citado projeto habitacional deuse sobre terreno que abrigava sítio arqueológico desconhecido, sobretudo pela falta de estudo de impacto ambiental, decorrente da obra, em descumprimento aos princípios basilares do 
Direito Ambiental e as disposições contidas na Lei $\mathrm{n}^{0}$ 6.938, de 1981 (dispõe sobre Política Nacional do Meio Ambiente), desprestigiando ao último nível o patrimônio cultural brasileiro.

\section{O PROJETO HABITACIONAL NOVA CIDADE E A AÇÃO CIVIL PÚBLICA}

Compulsando os autos do Processo Administrativo $n^{\circ}$ 01450.001139/2004-77, verifica-se que os documentos repassados pelo IPHAN não esclarecem, por exemplo, quais as licenças que as empresas possuíam para o início das obras.

Da mesma forma, não há esclarecimento acerca das licenças eventualmente concedidas pelo Instituto de Proteção ao Meio Ambiente do Amazonas (IPAAM), bem como se havia alguma ressalva sobre os estudos de impacto ambiental e sobre a necessidade de levantamento arqueológico. Ainda assim os trabalhos de terraplenagem foram iniciados no final do ano 2000 e início de 2001, quando, então, um fato chamou a atenção.

Compulsando os referidos autos, notou-se que, no dia 8 de janeiro de 2001, o IPHAN recebeu uma denúncia de moradores do entorno a qual alertava para a destruição de material de cunho supostamente arqueológico. Diante do ocorrido, o referido Instituto realizou uma vistoria no local e constatou que as ações de terraplanagem haviam destruído artefatos cerâmicos e urnas, causando danos irreversíveis aos vestígios arqueológicos ali sepultados. Revolvida a camada de terra antropogênica, contudo, à época ainda existiam pacotes de sedimento soterrados e vestígios arqueológicos não perturbados passíveis de fornecer 
informações para contextualizar o sítio e os vestígios destruídos. $\mathrm{O}$ tratorista que fez a terraplenagem relatou aos arqueólogos que pensava estar num local de fabricação de potes, tal a quantidade de vasilhames que encontrava.

Da análise dos autos, verificou-se que os técnicos do IPHAN, in loco, concluíram tratar-se de um sítio arqueológico de alta relevância científica, não somente devido à situação geográfica em terra firme, a quase $20 \mathrm{~km}$ de rio de maior porte, mas também em razão da espessura do refugo e das características culturais que permitem associá-lo, segundo o arqueólogo incumbido da ação emergencial, a pelo menos duas tradições culturais. Com efeito, suas dimensões foram estimadas em 500m x 500m, com camada arqueológica de mais de $1 \mathrm{~m}$ de espessura sobreposta à camada arenosa.

Ainda em sede de conclusões, os técnicos do IPHAN afirmaram que se configurava a hipótese de destruição intencional de sítio arqueológico, declarado patrimônio cultural brasileiro pela Constituição Federal, de 1988, e protegido pela Lei Federal no 3.924, de 1961, que impede seu "aproveitamento econômico" antes de devidamente pesquisado e formalmente liberado pelo Órgão competente. Concluíram também que, se as obras tivessem sido precedidas pelo EIA/RIMA, como determina a lei, a situação seria outra: o sítio e seu entorno não estariam completamente destruídos e seria possível obter dados mais detalhados, produzidos a partir de pesquisas sistemáticas de longo prazo.

Segundo informações contidas no Ofício $n^{0}$ 056/2004/ IPHAN/1 asR, de 9/3/2004, subscrito pela Superintendente do 
IPHAN à época (Processo Administrativo do IPHAN, pp. 123124), dirigido ao governador do estado do Amazonas, o objeto do referido ofício dava conhecimento direto ao governador sobre os fatos ocorridos no Projeto Habitacional Nova Cidade, solicitava providências cabíveis, entre as quais a criação de um Parque Arqueológico - Nova Cidade -, como forma digna de o Estado se redimir do crime cometido contra o Patrimônio Arqueológico e Ambiental, o primeiro da Amazônia.

Os documentos do IPHAN subsidiaram a Ação Civil Pública proposta pelo Ministério Público Federal (Processo Administrativo do IPHAN, pp. 55 e ss.) no dia 4 de dezembro de 2003 ( $n^{\circ}$ 2003.32.00.008189-1; 8184-75.2003.4.01.3200), contra IPAAM; SUHAB; e as empresas vencedoras do certame, todos por seus representantes legais. Segundo os autos, o Ministério Público Federal, às fls. 26-27 dos autos, definiu a responsabilidade de cada autor da seguinte forma:

DA RESPONSABILIDADE DA SUHAB Como entidade pública gerenciadora dos trabalhos de engenharia que estavam sendo realizados no local, não poderia ter iniciado as obras sem o devido estudo prévio de impacto ambiental. Tampouco poderia ter admitido o prosseguimento dos trabalhos de terraplenagem do terreno, especialmente após já haverem sido descobertos os inúmeros, valiosos e delicados exemplares dos potes cerâmicos, muitos dos quais estavam à flor do solo. A existência desses artefatos "dificultando" ou "atrapalhando" o desenrolar das obras são a maior prova de que a destruição, na forma e na escala em que se deu, não foi meramente acidental, antes, porém, consciente e delibera- 
da. Logo, compete-lhe, por meio de imposição do Poder Judiciário, cessar, de imediato, toda e qualquer atividade empreendida no local, bem como contribuir com a integral recuperação do local agredido. DA RESPONSABILIDADE DO IPAAM - Como entidade pública de fiscalização ambiental, em 1999 expediu licença ambiental para o início das obras, não tendo adotado os critérios técnicos indispensáveis para a verificação prévia da presença de eventual sítio arqueológico na área. Depois, porque não fiscalizou o desenrolar das atividades de construção, especialmente de terraplenagem, medida que, aliás, já poderia ter sido suficiente para evitar que houvesse a sistemática e intencional depredação dos artefatos arqueológicos. Segundo declarações, à época, da Diretora Técnica do Órgão, Sra. Maria do Carmo dos Santos, quanto ao assoreamento dos igarapés existentes no local como consequência dos trabalhos das construtoras, na ocasião da vistoria para emissão da licença, os fiscais verificaram que as margens dos igarapés estavam protegidas. Assim o IPAAM omitiu-se ao não acompanhar o desenvolvimento das obras do empreendimento, conduta que ocorreu tanto para a produção de danos ao meio ambiente natural (soterramento de igarapés), quanto ao meio ambiente cultural (ofensa ao sítio arqueológico). DA RESPONSABILIDADE DAS CONSTRUTORAS - Todas as empresas integrantes do empreendimento são corresponsáveis por todos os danos causados ao sítio arqueológico e ao meio ambiente natural. O empreendimento voltado à construção das unidades habitacionais populares (projeto habitacional Nova Cidade) consistia no gerenciamento pelo governo do Estado do Amazonas (SUHAB) de inúmeras obras que de- 
veriam ser executadas por um consórcio de empresas de construção; desmatamento e limpeza do terreno; infraestrutura e construção das casas, de ruas e das redes de esgoto, água, eletricidade e telefonia. Dessa forma, afigura-se patente que todas as empresas participantes do consórcio concorreram, direta ou indiretamente, para a prática dos ilícitos perpetrados contra o meio ambiente natural e o meio ambiente cultural (sítio arqueológico). DA RESPONSABILIDADE CIVIL AMBIENTAL - O princípio da responsabilidade objetiva, no que respeita aos danos contra o meio ambiente, está consubstanciado em diversos textos legais e na própria Constituição Federal de 1988, em seu Art. 225: “\$ $3^{\circ}$. As condutas e atividades consideradas lesivas ao meio ambiente sujeitarão os infratores, pessoas físicas ou jurídicas, a sanções penais e administrativas, independente da obrigação de reparar os danos causados.". No mesmo sentido a Lei ${ }^{\circ}$ 6.938/81, que estabelece a Política Nacional do Meio Ambiente, a qual, no seu artigo 14, caput, e no seu $\S 1^{\circ}$, determina: "Sem obstar a aplicação das penalidades previstas neste artigo, é o poluidor obrigado, independentemente da existência de culpa, a indenizar ou reparar os danos causados ao meio ambiente e a terceiros, afetados por sua atividade.". Logo, para se estabelecer a responsabilidade objetiva, basta se comprovarem a ocorrência dos atos e omissões dos demandados, os danos causados ao meio ambiente e ao patrimônio público e, finalmente o nexo causal, isto é, a comprovação de que condutas foram causas necessária e suficiente para que esses danos fossem provocados.

A magistrada, verificando a presença do fumus boni 
juris, com base no art. 20, X (que dispõe serem bens da União os sítios arqueológicos), c/c artigos $2^{\circ}$, "c" (consideram-se sítios arqueológicos os cemitérios, sepulturas ou locais de pouso prolongado ou de aldeamento, "estações" e "cerâmios" nos quais encontram vestígios humanos de interesse arqueológico) e $3^{\circ}$ (que proíbe, em todo o território nacional, a destruição ou mutilação das jazidas arqueológicas antes de serem devidamente pesquisadas) da Lei Federal n ${ }^{\circ} 3.924$, de 1961, e do periculum in mora pela descrição dos danos causados pela realização da obra, concedeu a liminar determinando a cessação das obras na área do sítio e do seu entorno pelos réus.

Após mais de uma década, em 6 de novembro de 2013, o Juízo Federal da $7^{\text {a }}$ Vara Especializada em Matéria Ambiental e Agrária do Estado do Amazonas realizou audiência na qual as partes manifestaram interesse na celebração da conciliação, sendo proferida decisão determinando que ficasse o IPHAN intimado para apresentar laudo técnico da situação da área objeto do processo, com o recolhimento do patrimônio arqueológico, bem como o valor que entendesse adequado a título de compensação pelo patrimônio arqueológico degradado. Após a apresentação da documentação pelo IPHAN, foi determinada a suspensão dos autos pelo prazo de 60 dias, a fim de que as partes buscassem uma composição acerca da questão.

Resumidamente, a minuta do Termo de Compromisso de Ajustamento de Conduta Ambiental sugeriu, entre outras medidas compensatórias, que os órgãos e construtoras envolvidos devem custear a contratação de uma equipe multidisciplinar, composta por arqueólogos, pedagogos e historiadores, para elaborar e 
executar um amplo Programa de Educação Patrimonial, sob a supervisão do IPHAN, por cinco anos, nas escolas públicas e particulares do Amazonas, sobre a importância do Patrimônio Cultural.

O IPAAM, por sua omissão em sua função fiscalizadora, ante o assoreamento dos igarapés e o grave processo erosivo por conta das obras, deverá apresentar um Plano de Recuperação de Área Degradada (PRAD), que será submetido ao IBAMA; a SUHAB e as construtoras, solidariamente, deverão providenciar a integração do sítio arqueológico Nova Cidade e seu entorno, a socialização do espaço, a implantação de um projeto que alie a preservação e contemplação informativa do patrimônio arqueológico, expondo in loco os artefatos que ainda estão presentes no local, aliados à prática de exercícios físicos, tudo isso sob a fiscalização do IPHAN.

\section{ELEMENTOS TEÓRICOS DO DIREITO AMBIENTAL}

Bechara (2009), de modo resumido, mostra que desde 1960 já havia uma dinâmica entre os Estados com vistas a uma regulamentação global do meio ambiente, algo que se materializou apenas em 1972, por ocasião da Conferência das Nações Unidas sobre o Meio Ambiente Humano, realizada em Estocolmo, na Suécia, que resultou na Declaração sobre o Meio Ambiente Humano e inspirou mais tarde a criação do Programa das Nações Unidas para o Meio Ambiente (PNUMA).

Passados 20 anos, ou seja, em junho de 1992, no Rio de 
Janeiro, com a presença de 170 países, realizou-se a Conferência das Nações Unidas sobre o Meio Ambiente e Desenvolvimento. Da conferência do Rio 92 surgiram diversas Convenções, como a Convenção sobre a Diversidade Biológica e a Convenção sobre Mudanças Climáticas, a Declaração do Rio de Janeiro sobre o Meio Ambiente e Desenvolvimento e a Agenda 21.

Segundo Bechara (2009), as declarações internacionais não têm força legal nem obrigam o cumprimento de seus termos aos seus signatários, como têm as convenções e tratados ratificados internamente; todavia, ajudam na elaboração e aplicação de normas ambientais. Quanto à Agenda 21, são propostas de diretrizes, políticas e medidas a serem realizadas pelos Estados no século XXI em prol do desenvolvimento sustentável.

A partir de Estocolmo, tanto no Brasil como nos demais países, as normas ambientais tornaram-se mais rigorosas e trouxeram avanços por conta de ações, abstenções e cautelas praticadas em decorrência da aplicação dessas leis. Um dos marcos legais no Brasil para o Direito Ambiental é a Lei n ${ }^{\circ} 6.938$, de 1981, que instituiu a Política Nacional do Meio Ambiente e incorporou uma série de princípios reconhecidos na Declaração de Estocolmo, muito embora existam normas precedentes que remontam a segunda metade dos anos 60, como o Código Florestal (Lei no 4.771, de 1965); a Lei de Proteção à Fauna (Lei $\mathrm{n}^{\mathrm{o}} 5.197$, de 1967); e a Lei do Zoneamento Industrial (Lei ${ }^{\circ}$ 6.803, de 1980).

Outro marco que influenciou todo o sistema jurídico brasileiro corresponde à Carta Constitucional de 1988, que trata 
o meio ambiente como direito fundamental essencial à sadia qualidade de vida (art. 225). Além disso, o art. 216, caput, incisos e parágrafos, da Constituição dispõe sobre o patrimônio cultural brasileiro e a responsabilidade da sua proteção contra danos e ameaças, sendo incluídos como parte desse rico patrimônio os sítios arqueológicos (art. 216, V, da CF, de 1988).

Com base nas lições de autores clássicos da ciência do Direito, em especial do Direito Ambiental, como Silva (2007) e Machado (2013), o meio ambiente pode ser concebido em quatro classificações: o meio ambiente natural; o meio ambiente artificial; o meio ambiente cultural; e, por fim, o meio ambiente do trabalho.

Para Silva (2007), a ação humana destruidora do meio ambiente manifesta-se de várias maneiras, dentre as quais cita: a) o desmatamento; b) a poluição; c) a degradação do solo; e, d) o poluidor e poluente. Nota-se que o autor não inclui expressamente o desenvolvimento de uma região, com suas obras de infraestrutura, como elemento de destruição do meio ambiente. Com efeito, sabe-se que, a fim de evitar lesões ao bem ambiental, toda obra deve passar por um processo de licenciamento, o que inclui ter o seu Estudo Prévio de Impacto Ambiental e o seu Relatório de Impacto Ambiental (EIA/RIMA), nos termos da Constituição.

Contradições entre a preservação ambiental e o chamado desenvolvimento econômico (mais adequado seria substituir a expressão "desenvolvimento" por "crescimento" econômico) geram situações que têm afetado com especial ênfase os bens ambientais. Obviamente, o interesse coletivo fica dividido entre 
a necessidade de preservação e a possibilidade de melhoria do nível econômico (comumente vista como decorrência quase lógica das obras de infraestrutura). Apesar disso, convém mencionar que, não raras as vezes, essas ações do Poder Público têm o condão de transformarem-se em verdadeiras promessas de progresso, nem sempre realizáveis.

Sabe-se que o ser humano faz parte do meio em que vive; por isso, a tutela jurídica do meio ambiente está interligada à vida humana. Deveras, a proteção do meio ambiente contempla desde o bem-estar coletivo até os aspectos culturais caracteristicamente predominantes numa civilização. Exatamente por isso foi criado um sistema jurídico-protetivo desse bem tão precioso. De fato, tal sistema encontra-se envolto em princípios do direito ambiental, tendo como um dos mais importantes o da fraternidade intergeracional, que visa garantir elementos para a revelação de nossa história amazônica, por meio da proteção e dos estudos de nossos sítios arqueológicos, por exemplo.

\subsection{O patrimônio cultural brasileiro}

Segundo a Declaração de Caracas de 1992, “o Patrimônio Cultural de uma nação, de uma região ou de uma comunidade é composto de todas as expressões materiais e espirituais que lhe constituem, incluindo o meio ambiente natural".

$\mathrm{Na}$ Constituição de 1988, no seu art. 216, caput e incisos, tem-se de maneira clara a definição de Patrimônio Cultural como sendo aquele constituído pelos bens de natureza material e imaterial, tomados individualmente ou em conjunto, 
portadores de referência à identidade, à ação, à memória dos diferentes grupos formadores da sociedade brasileira, nos quais se incluem: as formas de expressão, os modos de criar, fazer e viver; as criações científicas, artísticas e tecnológicas; as obras, objetos, documentos, edificações e demais espaços destinados às manifestações artístico-culturais; e os conjuntos urbanos e sítios de valor histórico, paisagístico, artístico, arqueológico, paleontológico, ecológico e científico.

Ao arrepio da lei, as obras em questão foram iniciadas sem as licenças necessárias e não houve, por parte dos órgãos responsáveis, fiscalização que impedisse a destruição irreparável dos bens arqueológicos ali situados ou que cobrasse o necessário estudo de impacto ambiental nos termos da Resolução nº 01 , de 1986, do CONAMA.

Com efeito, o licenciamento ambiental é um dos mais importantes instrumentos para a consecução da Política Nacional do Meio Ambiente, listado no inciso IV do artigo $9^{\circ}$ da Lei $\mathrm{n}^{\circ}$ 6.938, de 1981, sendo corolário da determinação constitucional direcionada ao Poder Público para controlar a poluição (artigo $\left.225, \S 1^{\circ}, V\right)$ e uma manifestação do poder de polícia ambiental (limite de ação do particular).

Por sua vez, prevê o caput do artigo 10 da Lei 6.938, de 1981, que "a construção, instalação, ampliação e funcionamento de estabelecimentos e atividades utilizadoras de recursos ambientais, considerados efetiva e potencialmente poluidoras, bem como os capazes, sob qualquer forma, de causar degradação ambiental, dependerão de prévio licenciamento do órgão estadual competente, integrante do Sistema Nacional do Meio Ambiente 
- SISNAMA, e do Instituto Brasileiro do Meio Ambiente IBAMA, em caráter supletivo, sem prejuízo de outras licenças exigíveis", sendo, portanto, prévia condição para o exercício das atividades econômicas poluidoras, realizando a exceção insculpida no parágrafo único do artigo 170 da Constituição.

A Portaria IPHAN 230, de 2002, é uma ferramenta que pode reduzir os danos arqueológicos decorrentes das obras e serviços virtualmente lesivos. Essa Portaria tem por finalidade compatibilizar as fases de obtenção de licenças ambientais com os estudos preventivos de arqueologia. Para isso, estabelece os procedimentos necessários nas fases de Licença Prévia (LP), Licença de Instalação (LI) e Licença de Operação (LO).

Dos artigos $1^{\circ}$ ao $4^{\circ}$ estão estabelecidos os trabalhos arqueológicos a serem adotados para a composição do EIA/ RIMA, e a consequente obtenção da Licença Prévia. Entre a finalização do EIA/RIMA e a expedição da Licença Prévia há o momento da audiência pública, no qual todos os estudos ambientais, dentre os quais estão os estudos arqueológicos, serão apresentados e debatidos com a sociedade. Por isso, desde esse momento é cabível a tratativa da questão da educação patrimonial, a ser trabalhada junto com o Poder Público local, a comunidade leiga e a comunidade arqueológica, num projeto que deve ser financiado, por força legal, pelo empreendedor.

A importância, para a proteção do patrimônio arqueológico, dos estudos arqueológicos serem sincronizados com as expedições de licenças, especialmente da Licença Prévia, assume maior destaque na consideração da decisão acerca da alternativa locacional e, dependendo do tipo de obra, 
nas discussões sobre as mudanças de traçado com a finalidade de melhor se atender à tutela dos bens arqueológicos.

Nessa fase inicial, vale destacar ainda a relevância do detalhamento do Termo de Referência para elaboração do Estudo de Impacto Ambiental. A menção genérica que deve ser feita por levantamento do potencial histórico, cultural e arqueológico deve ser substituída por termos mais precisos e detalhados que sejam aplicáveis ao caso concreto e que atendam à proteção do patrimônio arqueológico. Quanto mais claro, objetivo e detalhado o Termo de Referência, maiores serão as chances de sucesso na utilização dos instrumentos judiciais (tutela antecipada ou ação civil pública, por exemplo) e extrajudiciais (assinatura de Termo de Ajustamento de Conduta).

Os artigos $5^{\circ}$ e $6^{\circ}$ da Portaria $n^{\circ} 230$, de 2002, apresentam os procedimentos a serem adotados nas fases antecedentes às das Licenças de Instalação (LI) e de Operação (LO). A indicação do art. $5^{\circ}$ é a de que o Programa de Prospecção preveja também prospecções intensivas nos locais que sofrerão impactos indiretos potencialmente lesivos ao patrimônio arqueológico, como as áreas de reassentamento de população, expansão urbana e agrícola, serviços e obras de infraestrutura.

Os artigos $7^{\circ}$ e $8^{\circ}$ abordam a temática da educação patrimonial, imputando ao empreendedor a obrigação de arcar com os custos financeiros de programas destinados à gestão do material arqueológico resgatado. Esses artigos apresentam um diferencial em relação às diretrizes internas utilizadas pelo IPHAN.

A Portaria IPHAN n 28, de 2003, apresenta novidades 
que contribuem para a tutela efetiva do patrimônio arqueológico atingido por grandes obras. Nesse sentido, com o objetivo de minimizar os efeitos dos empreendimentos licenciados, os quais não contemplaram patrimônio, o artigo $1^{\circ}$ estabelece que os empreendimentos hidrelétricos de qualquer tamanho ou dimensão dentro do território nacional deverão ser estudados, resgatados e salvos, quando da renovação da licença ambiental de operação.

O IPHAN tem competência para exigir, a qualquer tempo, os estudos arqueológicos que não foram feitos durante o licenciamento, já que a responsabilidade do empreendedor é objetiva e não está elidida pela omissão do órgão licenciador ou por outros motivos que tenham suscitado a omissão injustificada da tutela dos bens arqueológicos.

\subsection{Princípios do direito ambiental}

No Direito Ambiental, os princípios não possuem uniformidade doutrinária na sua identificação nem no conteúdo jurídico. Eles estão consagrados na Constituição Federal ou em leis, resoluções, declarações extravagantes. Alguns merecem especial atenção na proteção dos sítios arqueológicos.

O princípio da prevenção se encontra implícito no art. 225 da Constituição Federal, em resoluções do CONAMA (exemplo disso é a resolução $\mathrm{n}^{\circ} 306$ de 2002), no preâmbulo da Convenção sobre a Diversidade Biológica e em outros diplomas legais. A prevenção pressupõe base científica para prever os impactos ambientais negativos decorrentes de determinada 
atividade lesiva ao meio ambiente, devendo-se impor aos empreendedores algumas condicionantes no licenciamento ambiental para reduzir ou suprimir os prejuízos. Utiliza-se esse princípio nas atividades em que já se tem vasto conhecimento, isto é, nos casos em que o risco é conhecido ou concreto, em que se sabe a extensão e a natureza dos males ambientais, em que se tenha uma boa margem de segurança para o trabalho. Em regra, busca-se sempre a prevenção dos danos ambientais, pois, na maioria das vezes, não é possível remediar os impactos desses agravos, em face de sua condição de irreversibilidade.

Pelo princípio do poluidor-pagador, aquele que causa degradação no meio ambiente deve responder pelos custos sociais resultantes da atividade lesiva. Esse princípio inspirou o $\S 1^{\circ}$ do artigo 14 da Lei $n^{\circ} 6.938$, de 1981, que prevê que "é o poluidor obrigado, independentemente da existência de culpa, a indenizar ou reparar os danos causados ao meio ambiente e a terceiros, afetados pela atividade", e está expresso no Princípio 16 da Declaração do Rio, de 1992.

O princípio do desenvolvimento sustentável tem previsão implícita na combinação dos arts. 225 e 170, IV, ambos da Constituição, e está expressamente contido no Princípio 4 da Declaração do Rio de Janeiro, de 1992. Por esse princípio, busca-se um equilíbrio entre desenvolvimento e preservação. Considerando-se que toda obra gera impactos, seu objetivo é otimizar o desenvolvimento e minimizar a degradação do meio ambiente. Com efeito, o tema abordado no presente artigo reflete de maneira clara esse princípio. Sabe-se da necessidade de se buscar o crescimento econômico de nossa região, ao mesmo 
tempo sabe-se da necessidade urgente de preservação de nossa sociobiodiversidade.

Os sítios arqueológicos podem representar pistas para se desvelar a história dos nossos antepassados, além de representarem um potencial turístico importante; contudo, sem o devido cuidado, a pressa pela realização de obras de desenvolvimento pode destruir essa riqueza ou sepultá-la de modo definitivo. Existem diversos precedentes e processos judiciais contra entes públicos que destruíram sítios arqueológicos e, consequentemente, o patrimônio cultural, em decorrência da execução de obras.

A solidariedade intergeracional ou equidade geracional, por sua vez, inspirou a parte final do art. 225, caput, da Constituição da República, quando impõe que a presente e as futuras gerações devem preservar o meio ambiente e adotar políticas ambientais, utilizando os recursos ambientais de maneira racional, evitando, assim, privar os seus descendentes de desfrutá-los. Esse princípio relaciona-se ao desenvolvimento sustentável, que busca exatamente a salvaguarda para as gerações vindouras. Segundo Amado (2011), há um pacto tácito entre a presente e as futuras gerações, visando à preservação e o acesso aos recursos ambientais a uma vida digna e sadia, razão pela qual as nações devem proteger os animais e vegetais ameaçados de extinção.

Os bens arqueológicos abrangem os elementos que permitem conhecer, eleger e interpretar as referências identificadoras da formação da sociedade brasileira, e constituem o legado das gerações passadas às gerações futuras. 
Assim, destruí-los significa subtrair a herança de seus legítimos herdeiros (CALDARELLI, 1997).

Segundo Soares:

Pelo princípio da equidade geracional, o Estado tem a obrigação de manutenção de um determinado número de sítios arqueológicos, de diversas épocas, intactos, total ou parcialmente, para que sua exploração possa ser beneficiada pelos progressos da técnica e pelo avanço dos conhecimentos arqueológicos, de acordo como processo decisório que envolva o contexto de seleção da geração futura. Esse princípio é um princípio ambiental já fortemente desenvolvido, mas pela estreita ligação que guarda com os princípios arqueológicos da Conservação in situ e da Matriz Finita será analisado sob o enfoque do patrimônio arqueológico. Se o estoque patrimonial não comporta renovação e pode simplesmente desaparecer no tempo presente, o acesso das gerações futuras aos bens arqueológicos somente será garantido pelo Poder Público atuar no sentido de possibilitar que todos os elementos necessários à pesquisa arqueológica e à realização de interpretações estejam seguros. Desse modo, a aplicação do princípio da conservação in situ. (SOARES, 2007, p. 117).

Os dados para a ponderação acerca da reserva do material arqueológico, seja pela conservação in situ, seja pela guarda adequada do material em laboratório sem a descontextualização de seu conjunto, para uma fruição futura (produção científica, utilização com finalidades sociais, dentre outros) são fornecidos pela Constituição Federal tanto pela previsão de garantia 
do acesso às fontes da cultura nacional (art. 215), como pelo entendimento expresso em vários dispositivos de que a produção do saber cultural, o desenvolvimento científico e a capacitação tecnológica ainda estão em construção em nosso país, num processo de evolução contínua, que depende do Poder Público, da sociedade e do fortalecimento dos processos decisórios públicos e participativos.

De acordo com Machado:

Sem dúvida, será sábio que, na era da precaução, as comunidades científicas cheguem a estruturar ou a reforçar instâncias coletivas de expertise, situadas a uma distância suficiente, tanto das administrações públicas como dos meios industriais e financeiros ou de organizações militantes. Ao mesmo tempo, certos papéis, como aqueles que tocam à definição dos problemas e das soluções aceitáveis, abrem-se, principalmente, ao cidadão através do debate público. É da interação entre o especialista e o cidadão, que se poderá esperar a formulação mais razoável das normas de comportamento face aos riscos, aos quais se pretende aplicar o princípio da precaução. (MACHADO, 2007, p. 47).

Cabe ao Estado proporcionar previsão de lei para estabelecer incentivos para a produção e conhecimento de bens e valores culturais ( $\S 3^{\circ}$ do art. 216); promover e incentivar o desenvolvimento científico, a pesquisa e a capacitação tecnológica (art. 218, caput); dar tratamento prioritário à pesquisa científica básica, nesta incluída a pesquisa com metodologia arqueológica ( $\$ 3^{\circ}$ do art. 218); apoiar a formação de recursos 
humanos nas áreas de ciência, pesquisa e tecnologia e conceder, aos que dela se ocupem, meios e condições especiais de trabalho ( $\left(3^{\circ}\right.$ do art. 218).

$\mathrm{O}$ conhecimento e a interpretação do patrimônio arqueológico, com questionamentos e interpretações pela próxima geração, devem, ao mesmo tempo, possibilitar a produção e utilização dos dados colhidos de acordo com os fatores políticos, sociais, econômicos, culturais e tecnológicos disponíveis e importantes para o momento, e a ponderação acerca da decisão de reservar, integral ou parcialmente, o estoque arqueológico pronto para ser explorado ou adiar o próprio processo decisório sobre tal exploração para o futuro.

Para Leite:

A democracia ambiental insere assim na teoria constitucional contemporânea, em caráter inovador, a participação de interesses não atuais como elemento pertinente e relevante a se considerado e efetivamente integrante dos processos de decisão. A democracia ambiental deve permitir que também os interesses e direitos das gerações futuras não sejam lesados, não apenas através da fiscalização da idoneidade da representação de seus interesses, mas, sobretudo, mediante a reserva da decisão à participação de seus legítimos interessados. (LEITE, 2000, p. 251).

A Declaração sobre as Responsabilidades das Gerações Atuais para as Gerações Futuras, Paris, UNESCO, 1997, estabelece que a liberdade de escolha deve se equânime entre as gerações e que é importante que sejam tomadas todas as 
providências necessárias para que as gerações presentes e futuras possam preservar sua diversidade cultural. Nesse sentido, há outra vertente igualmente importante do princípio da equidade intergeracional, que é o direcionamento das políticas públicas e das ações afirmativas para valorização dos grupos formadores da sociedade brasileira menos favorecidos: as comunidades indígenas e as remanescentes de quilombos.

Natureza Pública ou obrigatoriedade da Proteção Ambiental - Este princípio inspirou certa parcela do art. 225, caput, da Constituição da República, pois diz que é dever irrenunciável de o Poder Público promover a proteção do meio ambiente, por ser bem difuso indispensável à coletividade e à sadia qualidade de vida.

O princípio da participação, segundo Didier Junior (2010), remonta à Roma antiga, onde já existia uma concepção de responsabilidade e cuidado do cidadão em relação à República. Todavia, para Mancuso (2011), tal concepção tem origem grega e foi adotada pelos romanos. A participação popular em matéria de meio ambiente indica que toda pessoa tem o direito de participar ativamente das decisões políticas ambientais, em decorrência do sistema democrático, uma vez que os danos ambientais são transindividuais. Exemplo deste princípio é a necessidade da realização de Audiências Públicas em licenciamentos ambientais mais complexos (EIA-RIMA), nas hipóteses previstas pela Resolução do CONAMA 09, de 1987; na qual esta exigência é imprescindível na criação de Unidades de Conservação (consulta popular); na legitimação para propositura de ação popular ou mesmo no tradicional direito fundamental de petição ao Poder 
Público.

No caso tratado pelo presente estudo, verifica-se que o início do processo analisado deu-se pela manifestação popular, que, ao identificar o desrespeito ao patrimônio cultural, se manifestou de maneira democrática e participativa.

A função socioambiental da propriedade, tema em voga na atualidade, pressupõe que um dos requisitos para que a propriedade rural alcance a sua função social é o respeito à legislação ambiental (art. 186, II, da CF, de 1988), assim como a propriedade urbana, tendo em vista que o plano-diretor deverá necessariamente considerar a prevenção ambiental, a exemplo da instituição de áreas verdes. Nesse sentido dispõe o artigo 1228, $\S 1^{\circ}$, do Código Civil, que representa uma norma ambiental transversal que permeia todos os ramos do Direito. Com efeito, apesar de a propriedade constituir uma garantia constitucional consagrada, tal direito não é absoluto. O Estado, detentor do poder soberano, poderá, em virtude de interesse público, desapropriar a coisa do seu dono mediante prévia e justa indenização (art. 5, XXIV, da CF).

\section{CONCLUSÃO}

O presente artigo abordou desde a denúncia feita por populares ao Instituto do Patrimônio Histórico e Arquitetônico Nacional (IPHAN) até o Termo de Ajustamento de Conduta Ambiental (TACA). Da mesma forma, buscou-se evidenciar a importância dos bens ambientais que compõem o patrimônio cultural brasileiro e os princípios atinentes ao tema. 
Os direitos discutidos (moradia x patrimônio cultural) possuem avaliação diferenciada, pois, no ritmo de nossos tempos, o gestor público preocupa-se com o que entende por imediato (casas populares, neste caso). Verifica-se, em decorrência, uma preocupação menor com os elementos culturais imateriais e com a busca pela nossa identidade cultural com traços indígenas.

A situação retratada deixou evidente a importância da participação popular, quando cidadãos comuns procuraram o órgão adequado, IPHAN. A partir disso apurou-se uma série de atos que culminaram numa Ação Civil Pública pelo Ministério Público Federal.

Erigido à categoria de direito difuso fundamental pela Constituição de 1988, o meio ambiente ecologicamente equilibrado tem como principal obstáculo a falta de conscientização acerca da sua importância para a sadia qualidade de vida.

Em diferentes ocasiões, essa ainda frequente inaptidão para reconhecê-lo, na prática, como direito valioso, torna as ações de fiscalização menos efetivas, como ocorreu no desenvolvimento da obra construída sobre o sítio arqueológico Nova Cidade.

Passados mais de dez anos, ainda não se chegou a bom termo quanto aos objetos do processo, que continua na fase de composição, pela assinatura do Termo de Ajustamento de Conduta Ambiental, estando a obra ainda em construção, mesmo tratando-se, segundo especialistas, de um dos sítios arqueológicos mais importantes da América Latina. 


\section{REFERÊNCIAS}

AMADO, Frederico Augusto Di Trindade. Sinopse de direito ambiental: estudo recomendado para concursos públicos e Exames da OAB. Rio de Janeiro: Forense; São Paulo: Método. 2011.

BECHARA, Erika. Licenciamento e conservação ambiental na Lei do Sistema Nacional das Unidades de Conservação (SNUC). São Paulo: Atlas, 2009.

BRASIL. Constituição da República Federativa do Senado, 1988.

. Lei 4.771 de 15 de setembro de 1965 . Instituiu o Código Florestal (revogado pela Lei. 12.651 de 25 de maio de 2012). Publicada em 28 de setembro de 1965 no D.O.U.

. Lei 5.197 de 3 de janeiro de 1967. Dispõe sobre a proteção à fauna e dá outras providências. Publicada em 5 de janeiro de 1967 no D.O.U.

. Lei 6.803 de 2 de julho de 1980. Dispõe sobre as diretrizes básicas para o zoneamento industrial nas áreas críticas de poluição, e dá outras providências. Publicada em 3 de julho de 1980 no D.O.U. 
monumentos arqueológicos e pré-históricos. Publicada em 27 de julho de 1981 no D.O.U.

. Lei 5.869 de 11 de janeiro de 1973. Institui o Código de Processo Civil. Publicado em 17 de janeiro de 1973 no D.O.U.

. Lei 6.938 de 31 de agosto de 1981. Dispõe sobre a Política Nacional do Meio Ambiente, seus fins e mecanismos de formulação e aplicação, e dá outras providências. Publicada em 02 de setembro de 1981 no D.O.U.

. Lei 7.347 de 24 de julho de 1985. Disciplina a ação civil pública de responsabilidade por danos causados ao meio-ambiente e ao consumidor e dá outras providências. Publicada em 25 de julho de 1985 no D.O.U.

- Resolução $n^{0}$ 01/CONAMA de 23 de janeiro de 1986. Dispõe sobre critérios básicos e diretrizes gerais para a avaliação de impacto ambiental. Publicada no D.O.U., Seção I, p. 2548-2549, em 17 de fevereiro de 1986.

. Resolução n ${ }^{\circ}$ 306/CONAMA de 05 de janeiro de 1986. Dispõe sobre critérios básicos e diretrizes gerais para a avaliação de impacto ambiental. Publicada no D.O.U., Seção I, p. 2548-2549, em 17 de fevereiro de 1986.

. Portaria $\mathrm{n}^{\mathrm{o}}$ 230/IPHAN de 17 de dezembro de 2002. Publicada no D.O.U., n ${ }^{\circ}$ 244, em 18 de dezembro de 2002. 
. Portaria $n^{\circ}$ 28/IPHAN de 31 de janeiro de 2003. Publicada no D.O.U., $n^{\circ}$ 24, em 3 de fevereiro de 2003.

. $7^{\text {a }}$ Vara Federal do Amazonas, Ação Civil Pública n ${ }^{0}$ 8184-75.2003.4.01.3200.

CALDARELli, Solange Bezerra (Org.). Atas do Simpósio sobre Política Nacional do Meio Ambiente e Patrimônio Cultural: Repercussões dos Dez Anos da Resolução CONAMA $n^{\circ}$ 001/86 sobre a Pesquisa e a Gestão dos Recursos Culturais no Brasil. Goiânia, Fórum Interdisciplinar para o Avanço da Arqueologia/IGPA-UCG, 1997: 57-65.

CAMPOS, Helena Nunes. Princípio da proporcionalidade: a ponderação dos direitos fundamentais. Cad. de Pós-Graduação em Dir. Pol. e Econ. São Paulo, v. 4, nº 1, 2004.

DIDIER JUNIOR, Fredie. ZANETI JUNIOR, Hermes. Curso de direito processual civil: processo coletivo. v. 4, 5. ed. Salvador: JusPODIVM, 2010.

MACHADO, Paulo Affonso Leme. Direito ambiental brasileiro. 21. ed. São Paulo: Malheiros, 2013.

- O princípio da precaução e a avaliação de riscos. Revista dos Tribunais. São Paulo, ano 96, v.856, fevereiro de 2007. 
MANCUSO, Rodolfo de Camargo. Ação popular: Proteção do erário, do patrimônio público, da moralidade administrativa e do meio ambiente. 3. ed. São Paulo: RT, 1998, cap.2, p. 37-41.

LEITE, José Rubens Morato. Dano ambiental: do individual ao coletivo extrapatrimonial. São Paulo: Revista dos Tribunais, 2000 .

ONU. Declaração do Rio sobre Meio Ambiente e Desenvolvimento 1992. Disponível em: <http://www.onu.org. br/rio20/img/2012/01/rio92.pdf $>$. Acesso em 14 de junho de 2014.

SILVA, José Afonso da. Os Princípios Constitucionais Fundamentais. Revista do Tribunal Regional Federal $\mathbf{1}^{\text {a }}$ Região, Brasília, v. 6, n. 4, p. 17-22, out./dez. 1994.

SILVA, José Afonso da. Direito ambiental constitucional. 6. ed. São Paulo: Malheiros, 2007;

SOARES, Inês Virgínia Prado. Proteção jurídica do patrimônio arqueológico no Brasil: fundamentos para efetividade da tutela em face de obras e atividades impactantes. Erechim: Habilis, 2007.

Recebido em: 10/08/2014

Aprovado em: 20/08/2014 